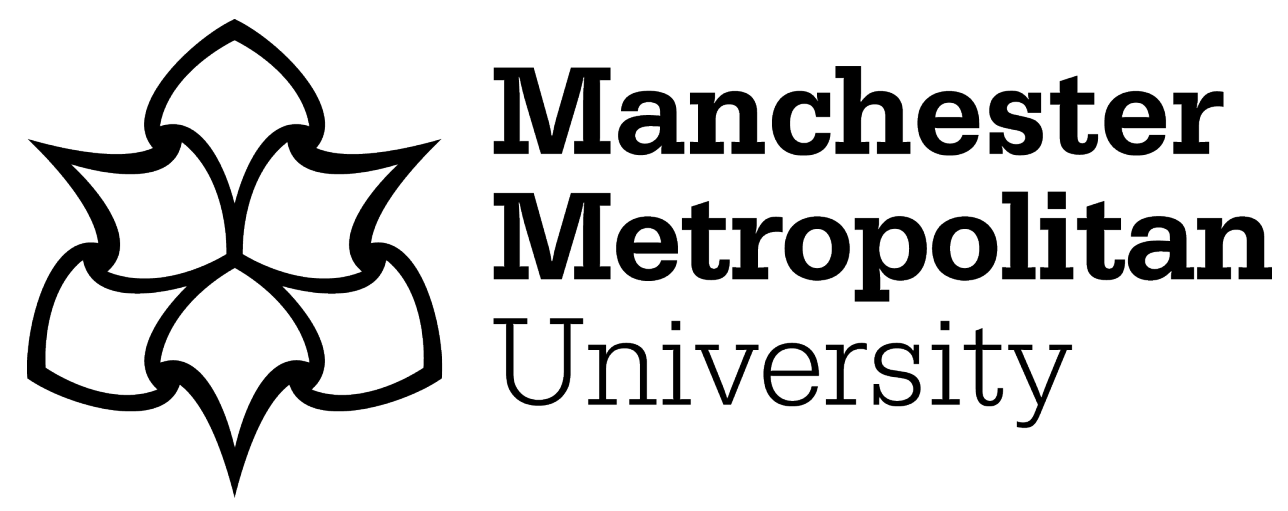

Urquhart, C ORCID logoORCID: https://orcid.org/0000-0001-7754-6085 (2019) Grounded Theory's Best Kept Secret: The Ability to Build Theory. In: The SAGE Handbook of Current Developments in Grounded Theory. Sage. ISBN 9781473970953

Downloaded from: https://e-space.mmu.ac.uk/619435/

Version: Accepted Version

Publisher: Sage

Please cite the published version 


\title{
GROUNDED THEORY'S BEST KEPT SECRET: THE ABILITY TO BUILD
}

\section{THEORY}

\begin{abstract}
While the power and influence of GTM as a qualitative research method in all academic disciplines continues to evolve and grow, the original intent of the founding fathers to build theory, and build it ambitiously, across and over different data sets and settings, seems to be rarely discussed in the literature. In particular, the recommendations from Glaser and Strauss in their 1967 Discovery book about building formal theory from substantive theory are rarely referenced. This chapter discusses how best to consider the recommendations from Glaser and Strauss with regard to not only building theory by minimising and maximising group differences, but by also considering the diversity or similarity of concepts within similar or dissimilar groups. An example of how such movements from substantive to formal theory might proceed is discussed, in order to explore and demonstrate those ideas in depth. The grounded theory approach to theory building is contrasted and critiqued against more mainstream ideas about theory building in various disciplines, and the debates about theory that exist in many applied disciplines. Finally, this chapter discusses how grounded theorists can actively take up these ideas within their own academic disciplines.
\end{abstract}

Keywords: Substantive and formal theory, maximising and minimising group differences, diversity and similarity of concepts in theory building, theory in academic disciplines

Cathy Urquhart, Manchester Metropolitan University, c.urquhart@mmu.ac.uk 


\section{Introduction}

As a lifelong passionate adherent of grounded theory method (GTM), and having watched GTM become more and more popular, and relevant, in a range of academic disciplines, I have one outstanding question. Why is it that the recommendations of Glaser and Strauss (Glaser and Strauss 1967) for moving from substantive to formal theory are not more widely discussed? If we take as our starting point Glaser and Strauss's definition of substantive theory, which is one developed for a substantive, or empirical area of enquiry, it is clear that the majority of theories generated using GTM fall into this definition. Why is it that we do not then attempt to build formal theory, which Glaser and Strauss define as one developed for a formal, or conceptual area of enquiry? Especially as Glaser and Strauss point out that substantive and formal theories exist on distinguishable levels of generality, and that each type can shade at points into the other?

Given an ongoing concern about theory building in many newer academic disciplines (Weber 2003, Lester 2005, Oswick, Fleming et al. 2011, Johnson, Ekstedt et al. 2012), which centre on those disciplines' ability to build formal theory, it seems timely to examine this question in more detail, and to explore GTM's undoubted contribution to a larger theory building effort in academic disciplines. While some social sciences have a long history of abstract theorizing eg Stinchcombe (1991), many newer disciplines do not. Even in those disciplines, the advice of Glaser and Strauss (1967) with regard to theoretical sampling, looking at dissimilar and similar groups with unsaturated and saturated categories, seems rarely acted upon, presumably because of some difficulties operationalizing the advice. I remain convinced that this advice gives us valuable guidance when building theory, because it gives us advice on extending the scope and generality of a theory, which in turn can lead us to building bigger, more formal theories.

The rest of this chapter looks at theory building debates in the newer academic disciplines, and considers GTMs contribution to the idea of theory. I then look at Glaser and Strauss's (Glaser and Strauss 1967) recommendations about theory building in detail, with special reference to minimising and maximising group differences. What might those recommendations tell us in 2017? What might we learn when we apply those recommendations?

\section{Theory, and Grounded Theory}

Glaser and Strauss (1967) set out the role of theory in sociology as both enabling prediction and explanation of behaviour, and also as 'being readily understandable to sociologists of any viewpoint, to students and to significant laymen'. They also state that the theory needs to be clear enough to be operationalised in quantitative studies where appropriate. They were also concerned with issues of fit of the theory, by which they meant that the theory must be able to explain the phenomena, and not be forced on to the phenomena as an explanation. Above all, they pointed out that enduring theories are based on data, are grounded in that data, and cannot easily be refuted (Glaser and Strauss 1967).They also made the important point that how theories are assessed is also dependent on how the theory was generated.

If we fast forward to recent debates about theory in management, and in information systems, we see some similar themes. For instance, Corley and Gioia (2011) are as concerned with the utility of a management theory as its originality. Oswick, Fleming et al. (2011) wonder if theory borrowing from 
other disciplines constrains the development of new and indigenous theories. This also raises issues of fit of those borrowed theories, and whether those theories are adequately grounded in data from their home discipline. In software engineering, the question has been raised about the absence of theories in the discipline (Johnson, Ekstedt et al. 2012), and the utility of theories to the discipline.

In information systems, a lively debate about the importance of theory to the discipline occurred in 2014. Avison and Malaurent (2014) railed against what they saw as a fetishing of theory in the discipline, the fact that various theories fell in and out of favour, and again, raised questions about the fit of borrowed theories. Their piece was accompanied by several commentaries from Lee (2014), Markus (2014), and (Gregor 2014). One striking agreement among the commentaries was that there was indeed a lack of consensus about what a theory is.

Overall then, we see in these debates a lack of consensus about what theory is, and also a concern about the fit of theories imported from older reference disciplines. While the first is probably attributable to the newness of some of these disciplines, it is interesting to note that there are also concerns about fit and groundedness of theories, whether imported from outside the discipline (fit), or groundedness (within the discipline).

Gregor (2006) is quoted in a number of these debates, and her definition of theory bears repeating here because it is both broad and helpful. She defines theories as 'abstract entities that aim to describe, explain, and enhance understanding of the world and in some cases, to provide predictions of what will happen in the future and to give a basis for intervention and action.'(p.616). She further categorises theories into those that analyse and describe (but do not contain causal relationships), theories for explanation (but with no testable propositions), theories for prediction (testable propositions but no causal explanations), and theories for both explanation and prediction. She also adds theories for design and action, which can be seen as more specific to information systems and software engineering.

Gregor also defines the components of all theories as containing a means of representation, constructs, statements of relationship, and scope. It is useful to consider how these conventional components compare to the grounded theory process of theory building, simply because it seems rarely that grounded theory is discussed in the same way as theory in general - yet the components are the same, as the table below comparing Gregor's components to GTM indicates.

\begin{tabular}{|l|l|l|}
\hline Theory Component & Definition & In Grounded Theory \\
\hline Means of representation & $\begin{array}{l}\text { The theory must be represented } \\
\text { physically in some way: in words, } \\
\text { mathematical terms, symbolic } \\
\text { logic, diagrams, tables or } \\
\text { graphically. }\end{array}$ & $\begin{array}{l}\text { Theories in GTM are often } \\
\text { represented by a narrative } \\
\text { framework, diagrams or } \\
\text { statements of hypotheses }\end{array}$ \\
\hline Constructs & $\begin{array}{l}\text { These refer to the phenomena of } \\
\text { interest in the theory (Dubin's } \\
\text { "units"). All of the primary } \\
\text { constructs in the theory should } \\
\text { be well defined. Many different } \\
\text { types of constructs are possible: } \\
\text { for example, observational (real) } \\
\text { terms, theoretical (nominal) } \\
\text { terms and collective terms. }\end{array}$ & $\begin{array}{l}\text { In GTM aim is to get to one } \\
\text { to two core categories or } \\
\text { constructs. This makes for a } \\
\text { more parsimonious and coherent } \\
\text { theory. All the constructs in a } \\
\text { grounded theory are grounded in } \\
\text { data, which can be equated to } \\
\text { observational (real) terms. }\end{array}$ \\
\hline
\end{tabular}




\begin{tabular}{|l|l|l|}
\hline Statements of relationship & $\begin{array}{l}\text { These show relationships among } \\
\text { the constructs. Again, these may } \\
\text { be of many types: associative, } \\
\text { compositional, unidirectional, } \\
\text { bidirectional, conditional, or } \\
\text { causal. The nature of the } \\
\text { relationship specified depends on } \\
\text { the purpose of the theory. Very } \\
\text { simple relationships can be } \\
\text { specified: for example, "x is a } \\
\text { member of class A." }\end{array}$ & $\begin{array}{l}\text { In Guatitative data, relationships are } \\
\text { not often described in } \\
\text { mathematical terms. There is a } \\
\text { lot of guidance in GTM about the } \\
\text { sort of relationships that are } \\
\text { possible between constructs, in } \\
\text { the form of coding families } \\
\text { (Glaser 1978) and a coding } \\
\text { paradigm (Corbin and Strauss } \\
\text { 2008) }\end{array}$ \\
\hline Scope & $\begin{array}{l}\text { The scope is specified by the } \\
\text { degree of generality of the } \\
\text { statements of relationships } \\
\text { (signified by modal qualifiers } \\
\text { such as "some," “many," "all," } \\
\text { and "never") and statements of } \\
\text { boundaries showing the limits of } \\
\text { generalizations. }\end{array}$ & $\begin{array}{l}\text { GTM aims to produce } \\
\text { substantive theories which } \\
\text { pertain to the area being } \\
\text { investigated. The scope and } \\
\text { generalisability can be extended } \\
\text { by theoretical sampling (Glaser } \\
\text { 1978). The substantive theory } \\
\text { can and should be engaged with } \\
\text { existing theories - in grounded } \\
\text { theory, existing theories can also } \\
\text { be seen as slices of data which } \\
\text { help build the theory. }\end{array}$ \\
\hline
\end{tabular}

Table 1 - Comparing Gregor (2006) components to grounded theory building (Urquhart, 2013)

A few points in the above table bear further discussion. First, and most importantly, the constructs in a grounded theory are grounded in data. Second, the founding fathers of grounded theory knew that a parsimonious theory was important - hence the recommendation that one or two 'core' categories (or constructs) should make up a grounded theory. This recommendation helps to raise the level of the theory and widen its potential scope. Third, grounded theories rarely have relationships described in mathematical terms, because they are grounded (usually) ${ }^{1}$ in qualitative data. That said, it is entirely possible to generate propositions about causal relationships in a grounded theory. If we look at the range of academic theories available to us, there are many different relationships represented in theories. For instance, in structuration theory (Giddens 1984) posits that social systems are created and reproduced by an inseparable duality of structure and agency. Theories like structuration theory are of course precisely the sort of 'grand' armchair theories that Glaser and Strauss (1967) felt did not provide sufficient theory for new areas, or simply did not work. Interestingly, Giddens did not think that his theory should be used for guiding practice of research, but rather as a sensitising device, which is entirely reasonable, as it can be seen as a 'grand' or formal theory'.

\footnotetext{
${ }^{1}$ Glaser, B. G. and A. L. Strauss (1967). The discovery of grounded theory: Strategies for qualitative research. New York, Aldine Publishing Company.and Glaser's monograph on quantitative GT - Glaser, B. G. (2008). Doing Quantitative Grounded Theory, Mill Valley Press. (2008) state that grounded theories can be built from quantitative data. Walsh, I. (2014). "Using quantitative data in mixed-design grounded theory studies: an enhanced path to formal grounded theory in information systems." European Journal of Information Systems 2014: 1-27., gives an interesting illustration of using quantitative GT in a grounded theory building process by means of cluster analysis in a mixed method study.

2 That said, Giddens' view of his own theory has been challenged by proponents of 'strong' structuration theory, in, for example, Stones, R. (2005). Structuration Theory. London, Palgrave.
} 
This brings us to the final point in the table, which is the issue of scope. The inevitable consequence of a grounded theory is that it tends to be a substantive theory, pertaining to the area being investigated, because if the theory needs to be grounded in data, it will naturally limit the scope of the theory to what can be observed in a single study. It is this issue of scope - and the associated boundary conditions and context - that seem to be less discussed in the literature. While in the physical sciences, boundary conditions are typically solutions expressed as equations, in the social sciences, these conditions are more likely to be boundaries of race, gender and class - and the truly universal theories might transcend these boundaries (Spatz and Kardas 2008). Davison and Martinsons (2016) have discussed the issue of theory scope in information systems, asking to what extent are the findings of a study strictly limited to the original context, and the importance of boundary conditions. Within grounded theory, there is a degree of clarity around the issue of scope, because it is clear that the scope of the theory can be extended by following the advice on theoretical sampling. The next sections look at Glaser and Strauss's definitions of substantive and formal theory, then examine their recommendations on moving substantive theory to formal theory, using theoretical sampling.

\section{Defining Substantive and Formal Theory}

Glaser and Strauss (1967) define substantive theory as 'that developed for a substantive, or empirical area of sociological inquiry' (p.32). They define formal theory 'that developed for a formal, or conceptual area of sociological inquiry' (p.32). They are careful to say that both types of theory can be considered middle range, and are not all inclusive 'grand theories'. Glaser and Strauss point out that substantive and formal theories only differ in terms of the degree of generality - that is the scope of the theory. Formal theory is created by comparative analysis among different kinds of substantive cases. So, gradually the scope is increased, by different contexts and boundary conditions, represented by different substantive cases.

They suggest that, for substantive theory, the theorist can select groups from the same substantive class, regardless of where they are found (p.53). They give the example of comparing an 'emergency ward' to all kinds of medical wards, in all kinds of hospitals, in all countries. If however one was to progress toward a formal theory, they suggest that it would be useful to see the emergency ward as a sub class of emergency organisations.

So let us look more deeply at the definitions of substantive and formal theory. One key difference is that formal theory categories are not underpinned by high empirical content ${ }^{3}$, despite the fact that they have their origin in empirical data. For the purpose of this table, categories can also be seen as constructs, as defined by Gregor (2006 ). In grounded theory, the aim is to get to one or two core categories for a parsimonious theory (Glaser 1978, Strauss 1987). This helps the researcher to get to a reasonable level of abstraction, and mitigates against having too many low level categories, sometimes an inevitable consequence of detailed line by line coding. Importantly, it helps the researcher to pull together and integrate the theory around one central concern. In turn, those core categories are underpinned by lower level categories that are firmly grounded in the data.

Substantive Theory

Formal Theory

\footnotetext{
${ }^{3}$ I am indebted to Udo Kelle for this insight, and for his very helpful comments on this chapter
} 


\begin{tabular}{|l|l|l|}
\hline Categories & $\begin{array}{l}\text { One to two core categories, } \\
\text { underpinned by many instances in the } \\
\text { data (high empirical content) }\end{array}$ & $\begin{array}{l}\text { Underpinned by very few instances in the } \\
\text { data. The categories that help build those } \\
\text { formal categories, however, are } \\
\text { underpinned by data. The formal theory } \\
\text { category or construct is usually abstract, } \\
\text { eg structure, process, role, identity, } \\
\text { network, social capital }\end{array}$ \\
\hline $\begin{array}{l}\text { Relationships } \\
\text { (Theoretical Codes) }\end{array}$ & $\begin{array}{l}\text { Ideas for the relationships come from } \\
\text { coding families or other theories, in } \\
\text { line with theoretical sensitivity. Those } \\
\text { relationships are 'grounded' in the } \\
\text { data, to the extent that they are } \\
\text { evidenced in theoretical memos and } \\
\text { write ups of the research }\end{array}$ & $\begin{array}{l}\text { Often the relationships or underlying } \\
\text { mechanisms are unique - this is what } \\
\text { distinguishes a formal theory. Again, the } \\
\text { relationships or mechanisms will often be } \\
\text { underpinned by empirics at the lower } \\
\text { level. }\end{array}$ \\
\hline Scope & $\begin{array}{l}\text { Scope is limited to the substantive } \\
\text { (empirical) area of enquiry and } \\
\text { pertains to the area being investigated }\end{array}$ & $\begin{array}{l}\text { Scope is extended by comparative analysis } \\
\text { between different types of substantive } \\
\text { cases }\end{array}$ \\
\hline
\end{tabular}

Table 2 Considering the differences between substantive and formal theory

As the scope of a substantive theory is extended towards a formal one, category or construct names by necessity become simpler, and more abstract, because that construct has to apply to a large number of substantive cases.

Relationships between constructs or categories in grounded theory are named 'theoretical codes' by Glaser (1978) in his famed book Theoretical Sensitivity. The idea of theoretical sensitivity, articulated in the 1967 book, is that the grounded theorist has to be sufficiently aware of theories and how they are constructed, in order to be able to construct their own. Glaser proposed 18 'coding families' in Theoretical Sensitivity that give inspiration for relationships between categories. These families (now totalling 41 , with the families proposed in Glaser (2005)) are themselves often inspired by how other theories conceptualise phenomena. A few examples of theoretical families are given below.

\begin{tabular}{|l|l|}
\hline Family & Comment \\
\hline $\begin{array}{l}\text { The } 6 \text { C's - Causes, Contexts, Contingencies, } \\
\text { Consequences, Covariances and Conditions }\end{array}$ & $\begin{array}{l}\text { This basic coding family, together with family 5, } \\
\text { the Strategy Family, was adapted by (Strauss and } \\
\text { Corbin 1990) as their coding paradigm of 'Causal } \\
\text { Conditions, Context, Intervening Conditions, } \\
\text { Action/Interaction Strategies and Consequences' }\end{array}$ \\
\hline $\begin{array}{l}\text { Process - Stages, staging, phases, phasing, } \\
\text { progresssions, passages, gradations, transititions, } \\
\text { steps, ranks, careers, ordering, trajectories, chains, } \\
\text { sequencings etc }\end{array}$ & $\begin{array}{l}\text { Glaser remarks that a process should have at least } \\
\text { two stages. }\end{array}$ \\
\hline $\begin{array}{l}\text { The Dimension Family - Dimensions, elements, } \\
\text { division, piece of, properties of, facet, slice, sector, } \\
\text { portion, segment, part, aspect, section }\end{array}$ & $\begin{array}{l}\text { As Glaser says, the more we learn of a category, the } \\
\text { more we see of its dimensions. Of all theoretical } \\
\text { codes, this is one that all researchers are likely to } \\
\text { use. It is also important to realise that, when } \\
\text { theorising, that we can privilege one dimension } \\
\text { over another - it can become a full blown category }\end{array}$ \\
\hline $\begin{array}{l}\text { The Type Family - Type, form, kinds, styles, classes, } \\
\text { genre }\end{array}$ & $\begin{array}{l}\text { Glaser says while dimensions divide up the whole, } \\
\text { types show variation in the whole. So, for instance, } \\
\text { you might have a number of styles of introducing a } \\
\text { problem in a conversation }\end{array}$ \\
\hline
\end{tabular}


The Strategy Family - Strategies, Tactics, mechanisms, managed, way, manipulation, manoeuvrings, dealing with, handling, techniques, ploys, means, goals, arrangements, dominating, positioning

Moment capture, when a quick intervention is critical to causing an optimal outcome, eg closing a deal

Frames, which are excavated through discourse patterns and are socio cultural in nature

Causal family, a relative of the 6 Cs family. This includes several aspects 1) Bias random walk 2) Amplifying causal looping 3) conjectural causation 4) repetitive causal reproductions 5) equifinality 6) reciprocal causation 7) Triggers 8) Causal paths 9) Perpetual causal looping
The Strauss and Corbin (1990) coding paradigm seems to be a mixture of this family and the first family.

This is a new theoretical code introduced in the 2005 book

Also in the 2005 book, and based on communication theory.

(Glaser 2005) gives some interesting nuances of causation in this theoretical code.

Bias random walk is where all variables are in a flux, 'then on the introduction of a crucial variable. then of a sudden all of the variables fall into organisation'

Amplifying causal looping, 'where consequences become causes, and one sees either worsening or improving progressions or escalating severity'

Conjectural causation, where it is not always easy to identify decisive causal combinations.

Repetitive causal reproductions, when a repeated action keeps producing the same consequences

Equifinality, where no matter what the causes and paths, the same consequence will occur

Reciprocal causation, where there is a similar interaction of effects or amplified causal looping.

Triggers, which are sudden causes that set off a consequence or set of consequences

Causal paths, used to intervene in changing or stopping a consequence

Perpetual causal looping, a mathematical model, an ordered calculated growth of increased size based on a set temporal path

Table 3 Examples of Theoretical Families from Glaser (1978, 2005), adapted from Urquhart (2013)

Of course, there is also guidance on relating categories in the Straussian version of grounded theory. Strauss in 1987 proposed a coding paradigm of conditions, consequences, interactions, strategies and consequences, using a procedure he named 'axial coding'. He says the purpose of this element of axial coding is to 'hypothesise about conditions, consequences, interactions, strategies and consequences', ie think about how the categories relate. Later, Strauss and Corbin (1990) published a further coding paradigm, which prompted the now famous dispute between Glaser and Strauss. It is interesting to note however, that the strictures about this paradigm moved from mandatory to optional, over time. The table below explains the evolution of the coding paradigm.

\begin{tabular}{|l|l|}
\hline Coding Paradigm & Comment on evolving use of paradigm \\
\hline $\begin{array}{l}\text { Conditions, consequences, interactions, strategies } \\
\text { and consequences (Strauss 1987) }\end{array}$ & $\begin{array}{l}\text { In the 1987 book, it is clear that the coding } \\
\text { paradigm is not an optional part of coding. } \\
\text { Researchers are told to 'follow the coding } \\
\text { paradigm' p. 81 }\end{array}$ \\
\hline
\end{tabular}




\begin{tabular}{|l|l|}
\hline $\begin{array}{l}\text { Causal Conditions, Context, Intervening Conditions, } \\
\text { Action/Interaction, Strategies and Consequences } \\
\text { (Strauss and Corbin 1990) }\end{array}$ & $\begin{array}{l}\text { In the } 1990 \text { book the paradigm is modified to } \\
\text { include different types of conditions, and actions }\end{array}$ \\
\hline $\begin{array}{l}\text { Conditions (causal, intervening, and contextual), } \\
\text { Actions/Interactions (strategic or routine tactics), } \\
\begin{array}{l}\text { Consequences (immediate, cumulative, reversible, } \\
\text { foreseen or unseen) (Strauss and Corbin 1998) }\end{array}\end{array}$ & $\begin{array}{l}\text { In the } 1998 \text { book, conditions are clustered } \\
\text { together, strategies are clustered under actions } \\
\text { and consequences elaborated on. }\end{array}$ \\
\hline $\begin{array}{l}\text { Conditions, interactions and emotions, } \\
\text { consequences (Corbin and Strauss 2008) }\end{array}$ & $\begin{array}{l}\text { In the } 2008 \text { book, the paradigm loses its } \\
\text { prominence and is presented as an optional } \\
\text { analytic tool for novice researchers. That said, the } \\
\text { conditional/consequence matrix, used in previous } \\
\text { editions to think about relationships between } \\
\text { micro and macro conditions, now has a more } \\
\text { central place in coding. }\end{array}$ \\
\hline
\end{tabular}

Table 4 The Evolving Nature of the Straussian Coding Paradigm (Adapted from Urquhart 2013)

Moving to the question of scope, Glaser and Strauss (1967), distinguish between scope of the population covered by the theory, and the conceptual level of the theory (p.52). So for a substantive theory, different groups would be selected of exactly the same substantive type - they give the example of federal bookkeeping departments. However, if the aim is to progress to formal theory, increasingly dissimilar - and larger - groups need to be selected. The key sentences in the 1967 book are as follows:

'when the sociologist's purpose is to discover formal theory, he (sic) will definitely select dissimilar, substantive groups from the larger class, while increasing his theory's scope. And he will also find himself comparing groups that seem to be non-comparable on the substantive level, but that on the formal level are conceptually comparable...For example, while fire departments and emergency wards are substantially dissimilar, their conceptual comparability is still readily apparent..it must be explained on a higher conceptual level.' (p.54), (author's emphasis)

Clearly, Glaser and Strauss considered in great detail, from the beginning, the differences between substantive and formal theory, and how to move from one to the other, from a practical point of view. The next section discusses their recommendations for theoretical sampling, which are rarely discussed in the grounded theory literature, despite the undoubted insights they give us for the theory building process.

\section{Glaser and Strauss's Recommendations for Building Theory using Theoretical Sampling}

It is very clear that Glaser and Strauss were engaged from the outset with practical considerations for building theory - for them, the key issue of what data to collect next was always controlled by the emerging theory. The great contribution of their chapter on theoretical sampling in the 1967 book was their assertion that the selection of comparison groups gave control over two aspects of the developing theory - first, conceptual level, and second, population scope. This is expressed in a table on p.58 of the chapter, reproduced in this section, that shows the consequences of minimizing and maximizing differences in groups, and considering the variations within the data of those groups. Obviously variations in the data are expressed by variations in categories. 
For Glaser and Strauss, the purpose of selecting groups is not about comparisons between and inside substantive groups, useful though that may be. Their criteria are 'theoretical purpose and relevance - not of structural circumstance' (p.48).

Glaser and Strauss also lay great stress on either maximising or minimising differences between groups to control 'theoretical relevance' (p.55) of data collection. They also point out that this then has a bearing on categories. For instance, if a similar group is chosen, many more instances of a category will be collected, while important differences might be spotted not noticed in earlier data collection. This is important for establishing the properties of a particular category, and Glaser and Strauss suggest that these properties are established before differences in groups are maximised.

When maximising differences between groups, data in a particular category will vary. This allows the researcher to think about the 'strategic similarities' between groups, which give the uniformities of scope within the theory. They state that maximising 'brings out the widest possible coverage on ranges, continua, degrees, types, uniformities, variations, causes, conditions, consequences, probabilities of relationships, strategies, process, structural mechanisms, and so forth, all necessary for elaboration of the theory' (p.57). We can see here too an early reference to theoretical coding (Glaser 1978) and a recognition that a widening of scope means that relationships between constructs have to be reconsidered. They summarise their recommendations in the following table:

\begin{tabular}{|c|c|c|}
\hline \multirow[t]{2}{*}{ Group Differences } & \multicolumn{2}{|c|}{ Data on Category } \\
\hline & Similar & Diverse \\
\hline Minimized & $\begin{array}{l}\text { Maximum similarity in data leads } \\
\text { to: } \\
\text { Verifying usefulness of category; } \\
\text { Generating basic properties; } \\
\text { Establishing a set of conditions } \\
\text { for a degree of category. These } \\
\text { can be used for prediction. }\end{array}$ & $\begin{array}{l}\text { Identifying/developing } \\
\text { fundamental differences under } \\
\text { which category and hypothesis } \\
\text { vary }\end{array}$ \\
\hline Maximized & $\begin{array}{l}\text { Identifying/developing } \\
\text { fundamental uniformities of } \\
\text { greatest scope }\end{array}$ & $\begin{array}{l}\text { Maximum diversity in data } \\
\text { quickly forces: } \\
\text { dense developing of properties } \\
\text { of categories; integrating of } \\
\text { categories and properties; } \\
\text { delimiting scope of theory }\end{array}$ \\
\hline
\end{tabular}

Table 5 Consequences of Minimizing and Maximizing Differences in Comparison Groups for Generation of Theory (Glaser and Strauss, 1967, p.58)

Another way of thinking about this table is that its key contribution falls into two areas. First, it helps us see that maximising differences between groups helps us extend the scope of the theory we are working on. Second, we can raise the conceptual level of our substantive theory by considering the categories themselves. In particular, we can consider the unsaturated categories in our analysis as a promising avenue to raise the conceptual level of the theory, by guiding us to more interesting groups. The fascinating thing about this table is that it draws attention not only to issues of scope, but issues of the data, as expressed by the categories themselves, and how considering categories can improve the quality and conceptual level of the theory.

While Eisenhardt (1989) popularised theoretical sampling for group differences, she did not consider theoretical sampling of concepts in the same way as suggested above. She however talked 
about within case comparison based on categories, which can be seen as a variation of sampling for concepts in the data. The differences in strategy between grounded theorists and mainstream qualitative researchers can perhaps be seen as a consequence of different methodologies for theory building - Eisenhardt (1989) used cases, while grounded theory methodology relies upon slices of data. So, how might these recommendations for theoretical sampling, as suggested by Glaser and Strauss, be carried out? What happens if we try and follow what the table suggests?

\section{Enacting the Recommendations for Theoretical Sampling}

In Urquhart and Vaast (2012), I briefly discuss what Glaser and Strauss's advice on theoretical sampling might mean in practice for generation of social media theory, and use the example of Facebook statuses. In this section, I expand in detail on that example, and the steps of theory building that I believe are implied by the table, in order for us to explore what can be learned from those recommendations.

Glaser and Strauss state that, at the beginning of generating a substantive theory, differences should be minimised in comparative groups. We can choose to minimise or maximise differences in groups along several dimensions, such as age, country, language, political affiliation and so on. Maximising those differences helps use theorise on relationships, conditions, patterns, and mechanisms (Glaser and Strauss 1967, p. 57). In our Facebook example explained below, we may wish to look at slices of data from other on line sources, such as personal blogs, Twitter feeds, or how a person responds to other comments from people below the line (BTL) when commenting on a news article. The theoretical sampling and choice of data slices depends on how the theory develops. It is important to realise that the motivations for theoretical sampling are theoretically motivated, it is not a question of simply verifying the category in various populations. How might we operationalise the advice from Glaser and Strauss on theoretical sampling, and how does it help the development of a theory? Each step in the example is cross referenced to Table 6 below.

Step 0

Let us imagine we are trying to understand how people use Facebook. Suppose we start with a group of individuals aged 18-25, based in the UK, who use Facebook. By coding their Facebook statuses, we can see that there are many instances of people actively managing their Facebook statuses. Those statuses are chosen, or curated, to give the best possible impression of that person's life and circumstances. We draw this conclusion from the data because there are very few statuses that do not portray the status owner as someone who is successful, surrounded by friends, and enjoying travel. We decide to call this concept or code 'curating'. At the same time, we notice another interesting, minority use of Facebook status - a very personalised status that seems to be aimed at only a few people who might understand it. This concept we choose to call 'personalising'. At this point then, we have a choice whether to pursue the theory development via saturated or unsaturated concepts (Lehmann 2010). What should we do next?

We can base our theoretical sampling on either 'curation' - what we could call maximum similarity in data, or 'personalising', what we could call a fundamental difference in the data as to how people approach their Facebook statuses. In this example we first choose to pursue the unsaturated concept 'personalising', in order to learn more about the category, and proceed to Step 1. 
We would then sample a new Facebook group, of the same age, 18-25, in the same country, for the unsaturated concept of Personalising. Thus group differences are minimised (it is a similar group) but we are pursuing diverse concepts in the data.

Our slices of data would actively seek out statuses that are Personalising, for the purpose of learning more about this particular category. This will quickly fill out the category and help us understand how it might vary in different circumstances. Obviously, both 'Curating' and 'Personalising' could be subsumed into a higher level concept of, say, 'Impression Management' as the theory increases in scope, and we could probably expect new categories to emerge, which can be aspects of 'Impression Management'.

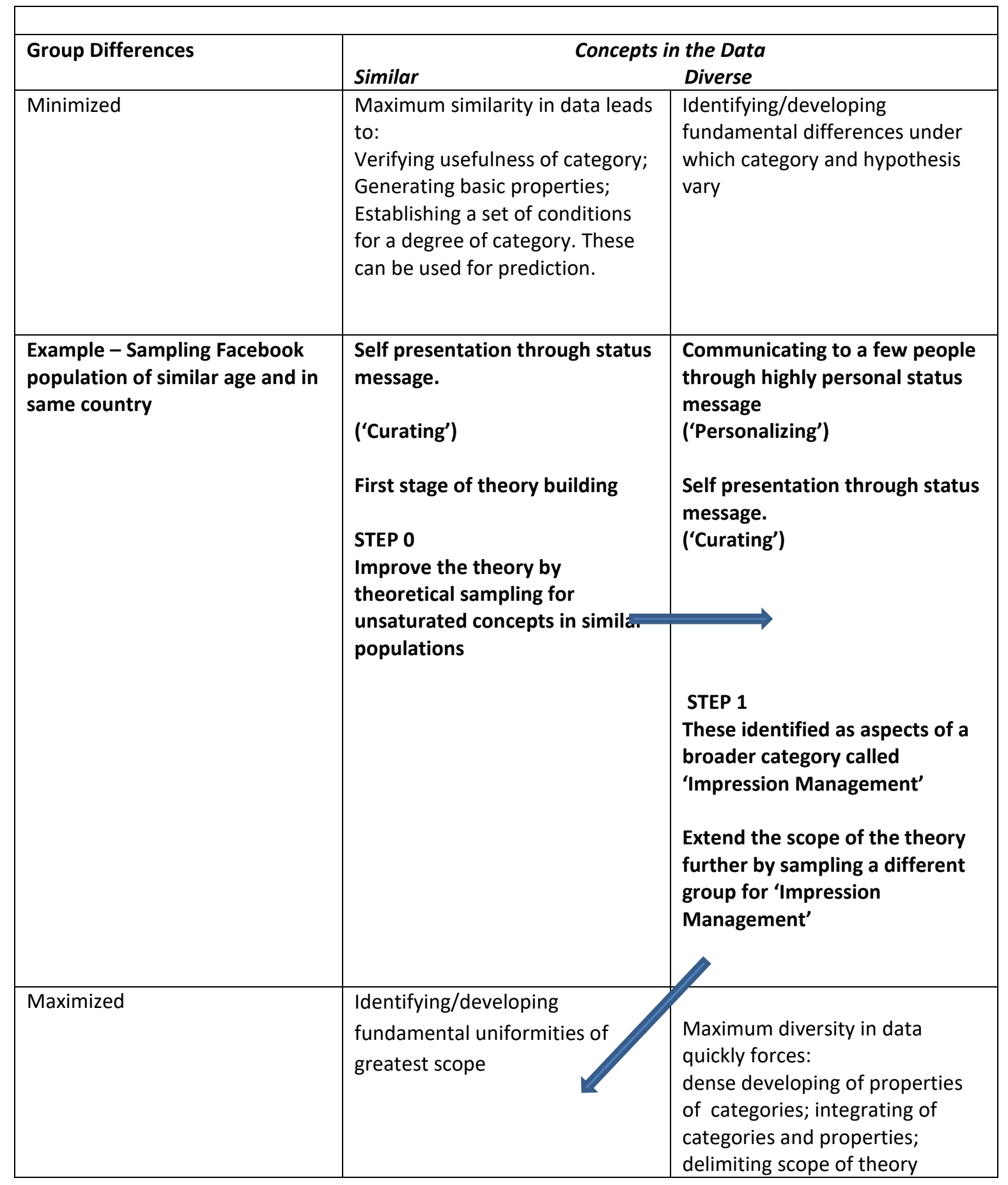




\begin{tabular}{|l|l|l|}
\hline $\begin{array}{l}\text { Facebook population - different } \\
\text { ages, different countries }\end{array}$ & $\begin{array}{l}\text { Managing of Facebook Status. } \\
\text { ('Impression Management' } \\
\text { consisting of 'Curating', } \\
\text { 'Personalising', and other } \\
\text { properties discovered) }\end{array}$ & $\begin{array}{l}\text { Sample for unsaturated } \\
\text { concepts discovered in previous } \\
\text { phase, to further extend the } \\
\text { theory scope and deepen the } \\
\text { category of Impression } \\
\text { Management }\end{array}$ \\
\hline $\begin{array}{l}\text { STEP 2 } \\
\text { Extend the scope of the theory } \\
\text { further by considering new } \\
\text { unsaturated concepts that } \\
\text { emerge }\end{array}$ & \begin{tabular}{l} 
STEP 3 \\
\hline
\end{tabular} & \\
\hline
\end{tabular}

Table 6 Example of Theory Building Using Glaser and Strauss's Recommendations for Comparison Groups

\section{Step 2}

We could then proceed to maximise group differences by sampling different age groups, and different countries, in order to deepen the theory and 'identify the fundamental uniformities of greatest scope'. In this stage, we will be paying attention to the saturated concepts of curating, and possibly personalising. This will further fill out the category 'Impression Management', which consists, at present of curating and personalising, and perhaps other types of Impression management discovered in Step 1. So, depending on how the theory is developing and the different properties of 'Impression Management', it might be apposite to sample a Facebook group that is older, or the same age range in a different country, so see if the categories hold true in a different culture. We could also consider whether membership of various Facebook groups has any sway on Impression Management. Thus the theory is increasing in depth in this stage. Impression Management is also a category that is quite abstract, which in future, may help us toward a formal theory.

\section{Step 3}

Again, we would be sampling a different group to maximise group differences, but also considering further unsaturated concepts that have been discovered in Step 2, to delimit the theory and densify the theory. At this stage, one could consider sampling slices of data not from Facebook but other online sources such as Twitter, or extending the age range further, or sampling more slices from people from various Facebook groups. Obviously, how those differences are maximised has a direct bearing on the theory development, and may also suggest new relationships between concepts. How the category of Impression Management is being filled out will suggests new avenues of theoretical sampling, until the theory is suitably densified and has adequate (theoretical) scope for the research purpose.

Note that this example gives but one route through the table, and it is a matter of judgement of how one might proceed through the table - the choice is to maximise group differences immediately, or 
pay attention to unsaturated concepts and deepening of the category while minimising group differences. My own preference is for the latter, as this seems to me the best way to deepen the theory by ensuring it is grounded in lots of instances from a similar group. It's also important to note how, as we might proceed to a formal theory, the category becomes more abstract (in this example, 'Impression Management') and not underpinned by empirical data, as this job is done by the lower level categories that underpin that more abstract category (in this example, 'Curating' and 'Personalising', and no doubt many other categories). To me the contribution of this table is not only understanding that we can extend the scope of a theory by paying attention to like and unlike groups, but that our theoretical sampling can be guided by our categories.

\section{Levels and Scope of Theory}

The previous section discussed, in detail, the guidance available from Glaser and Strauss for theory building using similar and dissimilar groups. It is helpful guidance, so, why is it not more known in the mainstream of qualitative research, and considered in numerous qualitative research textbooks consulted by graduate students? To me, the answer to this question resides in two places. First, in comparatively new disciplines like information systems and management, we are still unfamiliar with the process of theory building, and lack theoretical sensitivity, hence the debates on and lack of consensus on theory building in those two disciplines. Grounded theory is unique in how it encourages us to build theory systematically by use of constant comparison and theoretical sampling of groups. It also helps us understand, in detail, how theories shade into another from the substantive to the formal. So many of the newer disciplines lack deep appreciation for the structures of theories, conveyed in grounded theory by theoretical families and the coding paradigm, and by the idea of theory mechanisms in the social sciences.

Second, by contrast, in the social sciences, there has been indeed a great deal of debate about the nature of theory, largely focused on mechanisms. However, a lot of current discussion on mechanisms tend to focus on opening up the black box, and work from higher levels of theory to lower ones ${ }^{4}$ to provide explanations. Davison and Martinsons (2016) complain about a rush to universalism in the information systems discipline, where theories borrowed from other reference disciplines are applied, regardless of the context of that application. They make a plea for the understanding and clear explication of boundary conditions when using theories, lest the context of the study be ignored. My commentary on that article (Urquhart 2016), suggested that particularism vs universalism is a false dichotomy. Grounded theorists know that Glaser (1978) states that levels of theory shade into one another as a theory becomes more and more abstracted, from substantive to formal. Stinchcombe (1991) was keenly aware of the issue of levels of theory when writing about theory mechanisms in social science. His proposition was that paying attention to lower level mechanisms would result in a more 'supple' theory at the higher level. His definition of mechanisms is:

'1) a piece of scientific reasoning which is independently verifiable and gives rise to theoretical reasoning, 2) gives knowledge about a component process (generally one with units of analysis at a lower level) of another theory (ordinarily a theory with units at a different 'higher' level) thereby 3) increasing the suppleness, complexity, elegance or believability of the theory at a higher level without

\footnotetext{
${ }^{4}$ I am indebted to my colleague Olga Volkoff for this insight.
} 
excessive multiplication of entities in that higher level theory 4) without doing too much violence (in the necessary simplification at the lower level to make the higher level go) to what we know as the main facts at the lower level' p.367

This description will be immediately be recognisable to grounded theorists as a description of theoretical coding, and the need to ground those theoretical codes at the lower level, while at the same time making sure that the level of abstraction holds.

The figure below is offered as a summary of Glaser and Strauss' vision of theory building, without compromising the original vision. For me the key insight of their approach is not that we extend the scope of the theory by sampling different groups, but that we are theoretically guided by category development as we do so.

The $x$ axis represents Conceptual Level, and the $y$ axis Theory Scope. These are the two dimensions that are acted upon by following Glaser and Strauss' guidance on theoretical sampling. The process of sampling similar or dissimilar groups extends the scope, but it is by paying attention to saturated and unsaturated concepts that the conceptual level of the theory, and its direction, is considered and worked on.

\section{Theory Scope}

The starting point for theory building is a bounded context, where seed concepts are generated. These seed concepts might not even be empirically grounded, and little more than hunches (Urquhart, Lehmann et al. 2010). Substantive theories, which grounded theorists are very familiar with, pertain to the specific area being investigated, but the concepts generated in that theory exist independently of that data. Formal theories focus on conceptual entities. The scope of a theory is extended by sampling like and unlike groups, guided by concepts in the data. The suggestion here too is that boundary conditions are specified for each level of theory. In grounded theory terms, these boundary conditions are represented by theoretical codes and the categories. The suggestion of this figure (and Davison and Martinsons (2016)) is that these conditions and contexts should be clearly specified when a theory is published. 


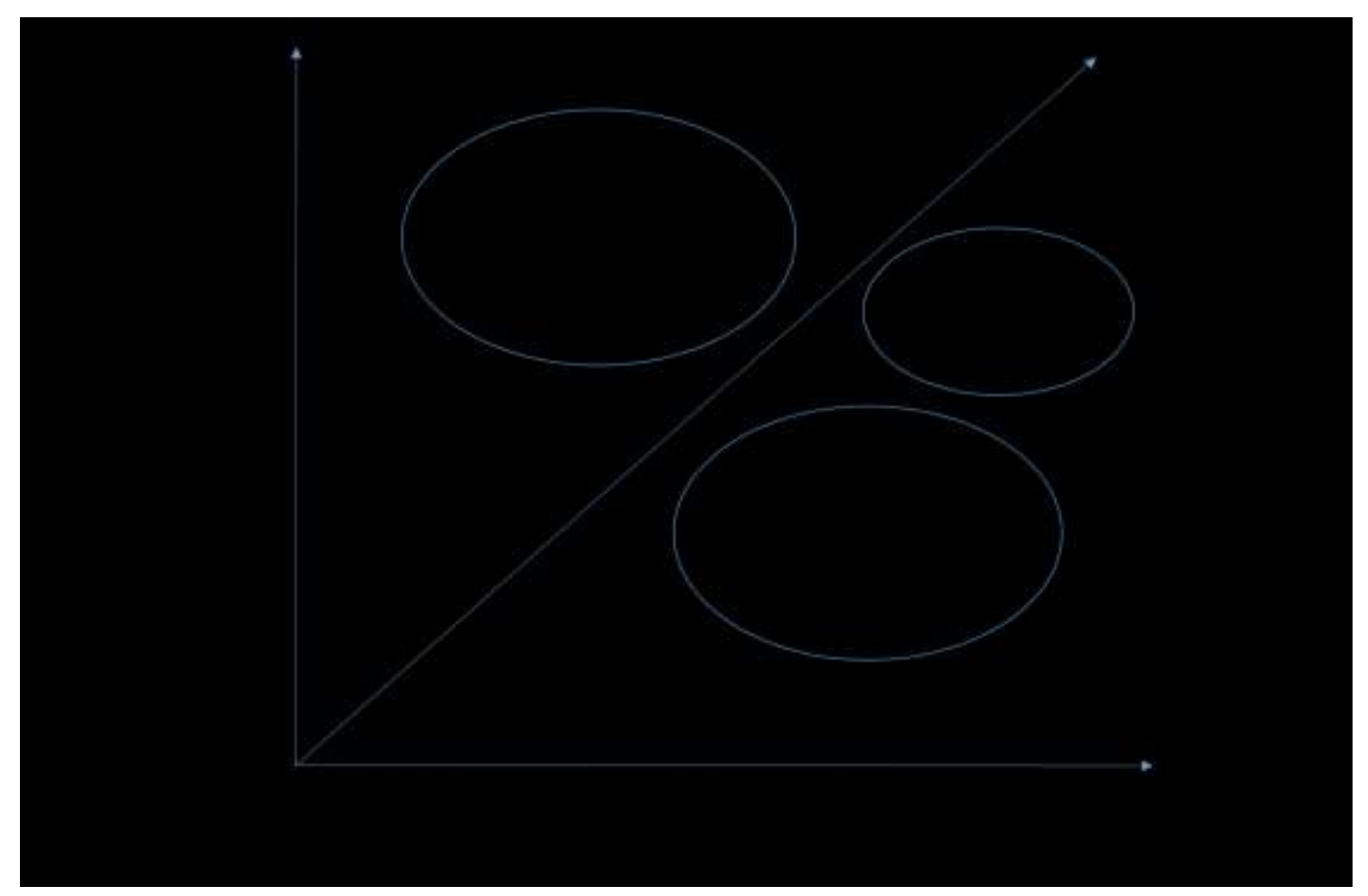

Figure 1 Theory Scope and Conceptual Level

\section{Conceptual Level}

When we first begin to code data, we inevitably code descriptively as it is necessary to explain the data to ourselves. As we begin to theorise about the data, and write theoretical memos, our concepts become more analytic, and less context dependent. The same applies to the relationships between concepts, where we have the challenge described by Stinchcombe (1991) of making sure the relationships we posit between concepts at the lower level also reside at the higher level.

\section{Discussion and Conclusion}

It is clear from the discussion that Glaser and Strauss did indeed have clear and systematic recommendations for theory building from 1967 onwards. One problem seems to be that, because grounded theory is seen as producing rich, qualitative theories that are about micro phenomena, these recommendations seem not have permeated into the wider academic disciplines we work in. Layder's critique (Layder 1998) about the hopelessly detailed nature of a grounded theory, it seems, has not been fully put to rest. It is easy to see why - the very nature of the grounded theory process means we start with a very detailed and inimate relationship with the data. This is both the strength and weakness of grounded theory. The scale of the task of building a grounded theory means that we often leave it to others to then take our theories, and either apply them to other contexts, or test them. One possible route is to take our substantive theories and widen their scope, but the emphasis on novelty, at least in my own discipline, seems to mean that once a substantive theory is published, it cannot be elaborated upon.

That said, my observation of the newer disciplines I work with - management, information systems and software engineering - is that these disciplines often struggle with theory building, and the nature of theory. Unlike my sociologist colleagues, we are largely unfamiliar with the notion of mechanisms or how formal theories are used. Grounded theory offers clear and practical guidelines 
on how a theory that applies to one area can be extended to another area, and also how the conceptual level of a theory can be pushed to levels of further abstraction. I would contend that newer disciplines can learn from the clarity and systematic nature of Glaser and Strauss's recommendations, because, for those disciplines, advancing new and larger theories are important. There seems to be very little discussion of levels of theory in the newer disciplines - theory is either treated as universal, generally coming from other reference disciplines, and grounded theories are not considered as contributions to the overall theory building effort. Worse, we seem to lack the language to discuss theory and theoretical contribution. In information systems, Burton-Jones, McLean et al. (2014) make an excellent contribution to the IS theory debate when they suggests moving away from ideas of process/variance theories that are prominent in the discipline, towards conceptual latitude and fit, and focusing on constructs and relationships. As Davison and Martinsons (2016) suggest, it would also be helpful if people using and advancing theories considered the context in which they were created, and the context in which they are subsequently applied. Categorising the type of theoretical contribution could also be fruitful; for instance, Colquitt and Zapata-Phelan (2007) suggest that contributions can be categorised from those which introduce significant new concepts, examine new relationships and processes, to those that attempt to replicate theories. They then consider to what extent that contribution is grounded, empirically or theoretically (Colquitt and Zapata-Phelan 2007).

The division between grounded theorists and their colleagues will hopefully fade as the division between qualitative and quantitative research recedes. Often, the phenomena itself will demand a combination of quantitative and qualitative research. We need to change policies via quantitative evidence, but before we do that, we need qualitative research into what people do. The advent of big data and the ubiquity of social media calls for both qualitative and quantitative research understanding patterns in data requires a qualitative understanding of why people do what they do. For too long, in my opinion, Glaser and Strauss' stellar contribution to understanding how we build theory, and how we scale up that theory, have been ignored by the mainstream of many of our academic disciplines. It is my sincere hope that this chapter contributes to interpreting the intentions of Glaser and Strauss's advice on theoretical sampling. Glaser and Strauss represent is a huge intellectual contribution to theory building in the twentieth and twenty first centuries, and these ideas can and should help theory builders everywhere.

\section{Acknowledgements}

I am very grateful to Udo Kelle, Stefan Seidel, Olga Volkoff and Hamid Pousti, all of whom gave extremely helpful comments on an earlier draft of this chapter.

\section{References}

Avison, D. and J. Malaurent (2014). "Is theory king?: questioning the theory fetish in information systems." Journal of Information Technology 29: 327-336.

Burton-Jones, A., E. McLean and M. E (2014). "Theoretical Perspectives on IS Research: From Variance and Process to Conceptual Latitude and Fit." European Journal of Information Systems $\mathbf{0 0}$ 1-16.

Colquitt, J. A. and C. P. Zapata-Phelan (2007). "Trends In Theory Building And Theory Testing: A FiveDecade Study Of The Academy Of Management Journal." Academy of Management Journal 50(6): 1281-1303.

Corbin, J. and A. L. Strauss (2008). Basics of Qualitative Research: Techniques and Procedures for Developing Grounded Theory. Thousand Oaks CA, Sage. 
Corley, K. and D. Gioia (2011). "Building Theory About Theory Building: What Consititutes A Theoretical Contribution?" Academy of Management Review Vol. 36 ( 1): p12-32.

Davison, R. M. and M. G. Martinsons (2016). "Context is king! Considering particularism in research design and reporting." Journal of Information Technology.

Eisenhardt, K. M. (1989). "Building Theories from Case Study Research." Academy of Management Review 14,: 532 - 550.

Glaser, B. G. (1978). Theoretical Sensitivity: Advances in the Methodology of Grounded Theory. Mill Valley, CA, The Sociology Press.

Glaser, B. G. (2008). Doing Quantitative Grounded Theory, Mill Valley Press.

Glaser, B. G. and A. L. Strauss (1967). The discovery of grounded theory: Strategies for qualitative research. New York, Aldine Publishing Company.

Glaser, B. J. (2005). The Grounded Theory Perspective III: Theoretical Coding. Mill Valley:CA, Sociology Press.

Gregor, S. (2006). "The Nature of Theory in Information Systems." MIS Quarterly 30(3): 611-642.

Gregor, S. (2014). "Theory - still king but needing a revolution!" Journal of Information Technology 29: 337-340.

Johnson, P., M. Ekstedt and J. I (2012). "Where's the Theory for Software Engineering?" IEEE

Software(September/October).

Layder, D. (1998). Sociological Practice: Linking Theory and Research. London, Sage.

Lee, A. S. (2014). "Theory is king? But first, what is theory?" Journal of Information Technology 29: 350-352

Lehmann, H. (2010). The Dynamics of International Information Systems: Anatomy of a Grounded Theory Investigation Springerlink.

Lester, F. K. (2005). "On the theoretical, conceptual, and philosophical foundations for research in mathematics education." ZDM 37(6): 457-467.

Markus, L. M. (2014). "Maybe not the king, but an invaluable subordinate: a commentary on Avison and Malaurent's advocacy of 'theory light' IS research." Journal of Information Technology 29: 341345.

Oswick, C., P. Fleming and G. Hanlon (2011). "From Borrowing To Blending: Rethinking The Processes Of Organizational Theory Building." Academy of Management Review 36(2): 318-337.

Spatz, C. and E. P. Kardas (2008). Research Methods in Psychology: Ideas, Techniques, and Reports, McGraw-Hill.

Stinchcombe, A. L. (1991). "The Conditions of Fruitfulness of Theorizing About Mechanisms in Social Science." Philosophy of the Social Sciences 21(3): 367-388.

Stones, R. (2005). Structuration Theory. London, Palgrave.

Strauss, A. and J. Corbin (1990). Basics of Qualitative Research: Grounded Theory Procedures and Techniques. Newbury Park, CA, Sage Publications.

Strauss, A. L. (1987). Qualitative analysis for social scientists. Cambridge, UK, University of Cambridge Press.

Strauss, A. L. and J. Corbin (1998). Basics of Qualitative Research. Techniques and Procedures for Developing Grounded Theory. London, Sage.

Urquhart, C. (2016). "Response to Davison and Martinsons: Context is king! Yes and no - It's still all about theory (building)." Journal of Information Technology. 31(3 ): pp.254-256.

Urquhart, C., H. Lehmann and M. Myers (2010). "Putting the Theory Back into Grounded Theory: Guidelines for Grounded Theory Studies in Information Systems." Information Systems Journal 20(4): 357-381.

Walsh, I. (2014). "Using quantitative data in mixed-design grounded theory studies: an enhanced path to formal grounded theory in information systems." European Journal of Information Systems 2014: 1-27.

Weber, R. (2003). "Editor's Comments: Theoretically Speaking." MIS Quarterly 27(3): iii-xii. 
